\title{
Excision of phaeochromocytoma and paraganglioma involving the
}

\section{great vessels}

U Srirangalingam, K Gunganah, L Parvanta, K Metcalfe, GM Besser, Berney D, Sahdev A, HS Flora, S Bhattacharya, R Carpenter, SA Akker, WM Drake, S J Edmondson.

St Bartholomew's Hospital, London, UK

\section{Objective}

- Phaeochromocytomas and paragangliomas occur across a wide distribution from the base of the skull to the pelvis, and may lie in close proximity to or involve the great vessels including the aorta and vena cava.

- The aim of the study was to describe the surgical management of phaeochromocytomas and paragangliomas involving the great vessels.

\section{Design}

- Retrospective case-series.

\section{Patients}

- 5 subjects undergoing surgical excision of either a phaeochromocytoma or paraganglioma involving the great vessels.

- Subjects were seen at St Bartholomew's Hospital, London between 2004 and 2013.

\section{Results}

- Five subjects (age range 16-60 years)

- Three subjects had thoracic paragangliomas located under the arch of the aorta.

- 1 subject had an abdominal paraganglioma in which preoperative imaging was unable to delineate that the tumour was invading the aorta.

- 1 subject had a massive phaeochromocytoma invading the IVC.

- Three of the 4 subjects tested had predisposing germline mutations

\section{- 2 subjects with $S D H B$ mutations}

- one subject with an SDHA mutation

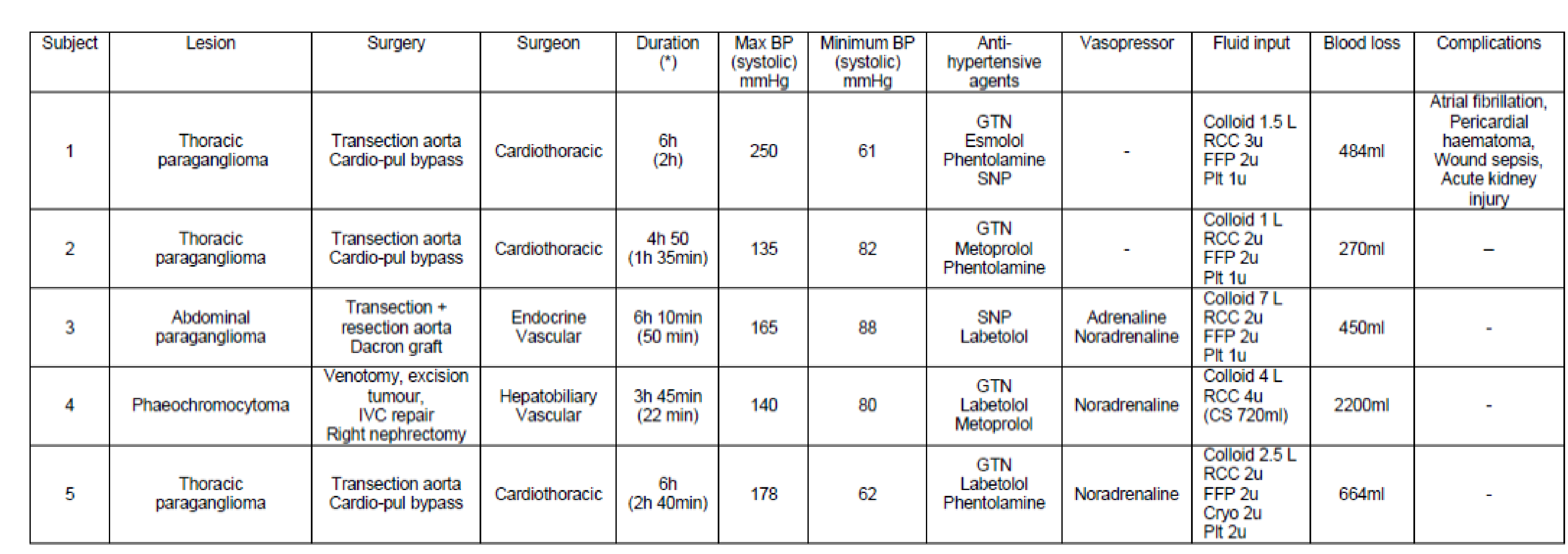

\begin{tabular}{|c|c|c|c|c|c|c|c|c|c|c|c|c|c|c|c|}
\hline Subiect & & $\begin{array}{l}\begin{array}{c}\text { Germine } \\
\text { mutation }\end{array}\end{array}$ & Lesicn & Siralcm & Great vesse & $\begin{array}{l}\text { Great vessel } \\
\text { involvem }\end{array}$ & $\begin{array}{l}\text { MBGG } \\
\text { imaging }\end{array}$ & $\begin{array}{l}\text { FDS } \\
\text { PET } \\
\text { Imaging }\end{array}$ & Hipetenson & & & & & 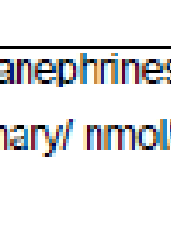 & \\
\hline & & & & & & & & & & $<560$ & <144 & 3194 & 2000 & 4400 & $<2500$ \\
\hline 1 & 60 & Not done & Thoracic & $4.8 \times 5.1$ & Aorta & Under arch & Avid & & Yes & 3677 & $<0$ & 2501 & & - & \\
\hline 2 & 40 & SOHE & Thoraacic & $5.1 \times 3.9$ & Aotra & Under arch & Nonavid & Avid & No & 356 & $<0$ & 2009 & & & \\
\hline 3 & 16 & SOHE & Adrdoninal & $6.5 \times 5 \times 4$ & Aotra & Inrading & Avid & Avid & No & 2863 & 57 & 3287 & & & \\
\hline 4 & 50 & Nil & Phaeociromocyloma & $12.6 \times 72$ & $\mathrm{Nc}$ & Inrading & Avid & & $\mathrm{M}$ & & & & 41481 & 718 & 10011 \\
\hline 5 & 49 & SOHA & Thoratic & $5.5 \times 3.5$ & Aota & Undererach & Ava & Avid & Yes & & & - & 11625 & 509 & $13300 \mathrm{C}$ \\
\hline
\end{tabular}

\section{Results}

- All subjects had alpha and beta adrenergic blockade prior to surgery.

- Thoracic paragangliomas were excised following cardiopulmonary bypass and aortic transection to access the tumours.

- Abdominal paraganglioma invading the aorta was resected with part of the aorta to clear disease + insertion of an aortic Dacron graft.

- Phaeochromocytoma invading the IVC - resected en bloc with the right kidney. Intra-operatively it was possible to resect the tumour nodule invading the IVC excised via a venotomy and vena cava repair.

\section{Outcomes}

- All subjects made a good recovery from surgery.

- One subject had early post-operative complication managed conservatively.

- One subject required adjuvant radiolabelled MIBG therapy for residual disease.
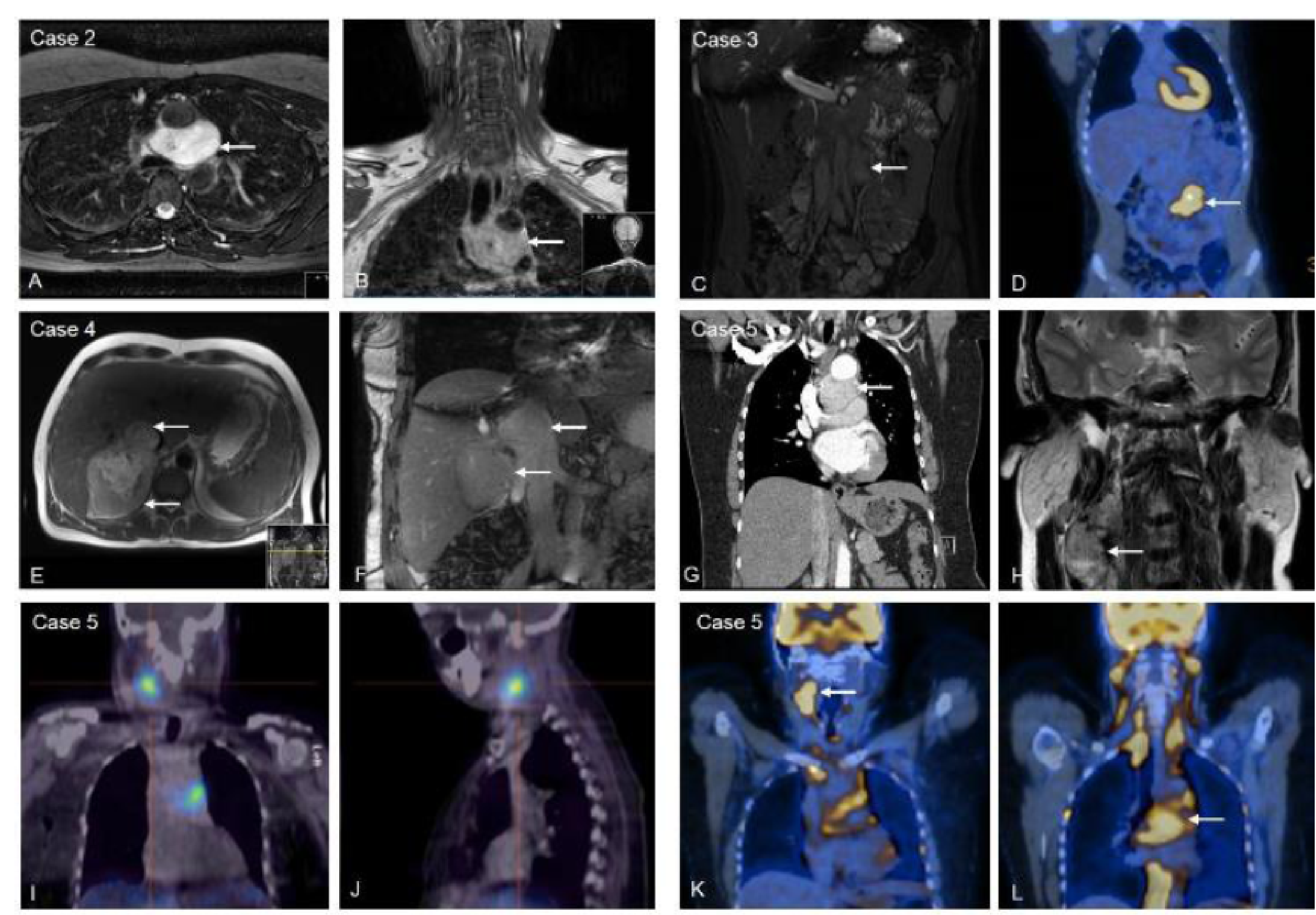

\section{Conclusions}

- Excision of phaeochromocytomas and paragangliomas involving the great vessels is high-risk surgery and should be undertaken in a tertiary referral centre within a multidisciplinary setting. Subjects require comprehensive radiological and biochemical assessment.

- Meticulous pre-operative preparation and appropriate intra- and post-operative back-up are essential.

- In some cases radiological imaging is unable to resolve the tumour anatomy and extent pre-operatively and direct visualisation of the tumour may be the only way to clarify the surgical strategy.

- Pre-operative knowledge of the genetic predisposition may influence surgical management. 